\title{
Kierkegaard, a Escola da Angústia e a Psicoterapia
}

Kierkegaard, the Anguish's School and Psychotherapy

Kierkegaard, la Escuela de La Angustia y la Psicoterapia

\section{Ana Maria Lopez Calvo de Feijoo \\ \& Myriam Moreira Protasio \\ Universidade do Estado \\ do Rio do Janeiro}

Débora Gill

Pontifícia Universidade

Católica Rio do Janeiro

Luiz José Veríssimo

Universidade Veiga de Almeida

http://dx.doi.org/10.1590/1982-370300912013 
Resumo: Este artigo busca refletir sobre a relação estabelecida por Soren Kierkegaard, na voz do pseudônimo Vigilius Haufniensis, entre angústia e Psicologia. A Psicologia surge, nesse contexto, como a ciência cuja atmosfera é angústia. Primeiramente, são apresentadas as considerações de Haufniensis sobre a angústia como determinação existencial. Em seguida, exemplificam-se as formas particulares de expressão da angústia por meio de um conto de Grimm, intitulado João sem medo. Observa-se que é da tensão entre o universal e o particular que nasce, por um salto qualitativo, a possibilidade de uma existência singular. Ao considerar o tema angústia como centro de investigação, e tendo como intuito pensar uma proposta de psicoterapia, conclui-se que o pensamento da existência, tal como desenvolvido por Haufniensis, proporciona elementos para a elaboração de uma proposta de psicoterapia que não se ocupe nem em julgar nem em teorizar, mas que sustente a existência como espaço onde tudo aparece como possibilidade.

Palavras-chave: Kierkegaard. Angústia. Psicoterapia. Escola.

Abstract: This article aims to reveal the association established by Soren Kierkegaard, under his pseudonym Vigilius Haufniensis, between anguish and psychology. The psychology arises in this context as the science whose atmosphere is anguish. First, we present Haufniensis' considerations about anguish as an existential determination. Then, we illustrate anguishspecific expressions through a Grimm's fairy tale called John Without Fear. Notes that it is from the tension between the universal and the particular that arises, by a qualitative leap, the possibility of a singular existence. We considered anguish as the subject of this research to elucidate a proposal of psychotherapy based on the elements provided by Haufniensis. This psychotherapy does not judge nor theorize but sustains the space of existence where everything can appear possible.

Keywords: Kierkegaard. Anguish. Psychoterapy. School.

Resumen: Este artículo trata de una reflexión sobre la relación que se establece, por Soren Kierkegaard en la voz del pseudónimo Vigilio Haufniensis, entre la angustia y la psicología. La psicología se plantea en este contexto, como la ciencia cuya atmósfera es la angustia. En primer lugar se presentan las consideraciones sobre la angustia como una determinación existencial. Entonces ejemplifican a las formas particulares de expresión de la angustia a través de una historia de Grimm, titulada John sin miedo. Se observa que es por medio de la tensión entre lo universal y lo particular que, con un salto cualitativo, nace la posibilidad de una existencia singular. Tomando el tema de la angustia como centro de investigación y que tiene la intención de pensar en una propuesta de la psicoterapia, se concluye que el pensamiento de la existencia, desarrollado por Haufniensis proporciona elementos para la elaboración de una propuesta de psicoterapia que no se ocupa ni en juzgar ni en teorizar, sino mantener la existencia de un espacio en el cual todo aparece como una posibilidad.

Palabras-clave: Kierkegaard. Angustia. Psicoterapia. Escola.

\section{Introdução}

A relação entre angústia e Psicologia é explicitada por Kierkegaard (1844/2010), na voz do pseudônimo Vigilius Haufniensis, em seu livro O Conceito de angústia. A Psicologia surge, neste contexto, como a ciência cuja atmosfera mais característica é a angústia, a qual se constitui como possibilidade que, de um modo ou de outro, se concretiza. À Psicologia cabe lidar com a situação de abertura - possibilidade - que determina a forma de toda existência e que se mostra como angústia.

Kierkegaard (1844/2010), sob o pseudônimo Haufniensis, aponta para a universalidade da angústia enquanto determinação existencial que, no entanto, assume formas particulares na vida de cada um. É desta tensão entre o universal e o particular que nasce, por 
um salto qualitativo, a possibilidade de uma existência singular. A singularidade, portanto, não é dada desde sempre, mas precisa ser conquistada, ou seja, não estando pronta precisa ser formada. A ideia de formação tem como pressuposto a angústia do homem sugerindo, deste modo, uma maneira de se transformar e aprender a partir deste caráter. Da indeterminação, característica do nada da angústia, surge o ser-capaz-de, ou seja, o poder se formar. Haufniensis vai designar a Psicologia como a ciência mais apta a lidar com este espaço de angústia, com este interlúdio, uma vez que nesta área não cabe teorizações, mas a sustentação deste espaço onde "tudo é possível". Consideramos que é a partir das considerações de Kierkegaard (1844/2010), na voz de Haufniensis, que poderemos pensar a possibilidade de uma psicoterapia kierkegaardiana (Feijoo, 2000; Feijoo e Protasio, 2011).

\section{João sem medo: aprendendo a angustiar-se}

No início do $\mathrm{V}$ capítulo de $O$ conceito de angústia, Kierkegaard (1844/2010), na voz de Haufniensis, relaciona a angústia com o aprender a angustiar-se. Neste capítulo, o autor alude a um conto de Grimm sobre um jovem, João sem Medo, que teria saído pelo mundo na aventura de aprender a angustiar-se (Grimm, 2004). Demoremo-nos um pouco neste conto, tecendo algumas considerações inspiradas no pensamento do pseudônmo Haufniensis (Kierkegaard, 1844/2010). O jovem não conseguia aprender nada, nem entender coisa alguma, tampouco se encaixava nos padrões da comunidade. $\mathrm{O}$ povo dizia: "este rapaz dará problemas a seu pai" (Grimm, 2004, p. 4), visto que ele não alcançava o que se esperava de alguém, isto é, que trabalhasse, que se casasse, que fosse razoável, etc. Quando o pai disse a João que ele estava ficando grande e forte e que já era hora de aprender algo que the permitisse ganhar o pão, João respondeu que gostaria de aprender a ter medo. Mas para o pai "não se vive disso" (Grimm, 2004, p. 5), ou seja, aprender a ter medo não vale nada pra vida. E para o irmão (que realiza as tarefas ordenadas pelo pai e que sente medo ao voltar para casa tarde da noite), João é tão estúpido que "nunca servirá para nada" (Grimm, 2004, p. 5). A partir daí, podemos ver que já existe para o pai e para o irmão uma determinação sobre como se deve viver: vive-se para garantir o pão, vive-se segundo um utilitarismo pragmático, para o que se considera necessário. Aprender a angustiar-se é um aprendizado completamente sem sentido para quem se ocupa dos afazeres práticos, com finalidades instituídas previamente.

Inicia-se um exercício para "provocar" a urgência do medo em João, segundo os moldes daquilo que faz temer. Mas a indiferença de João ao medo causou grande desgosto no pai, que acabou por expulsá-lo de casa, acreditando que as suas andanças pelo mundo o ensinariam a temer. $\mathrm{O}$ jovem se depara com aquilo que se costuma tomar como aterrorizante: fantasmas, cadáveres, caveiras, animais ameaçadores, e nada teme, pois não segue o que foi determinado como "isso é para temer". A estória finda com o herói finalmente assustando-se com uma coisa aparentemente inofensiva, com pequenos peixes pulando em sua barriga enquanto dormia. Eles foram postos sobre o seu corpo por sua esposa, que não aguentava mais a insistência de João em se lamentar de que não conseguia aprender a ter medo. $\mathrm{O}$ que daí se pode apreender é que o susto de João se constitui numa situação cotidiana da existência, não adianta querer defini-lo por antecipação, fabricando filmes de terror. O autor (Grimm) parece estar, com este conto, acenando para a importância de aprender a angustiar-se.

Kierkegaard (1844/2010), sob o pseudônimo Haufniensis, nem se preocupa com a resolução da estória. Ele prefere deixar o aventureiro seguir seu caminho e se detém em nos admoestar que o aprender a angustiar-se é "uma aventura pela qual todos têm de passar [...] para que não venham a perder, nem por jamais terem estado angustiados nem por afundarem na angústia" (Kierkegaard, 1844/2010, p. 163). A angústia está aí, existir é angustiar-se. E por isso, podemos pensar uma escola da angústia, uma escola acerca de si mesmo. Vamos, a partir de agora, nos 
1 Para este trecho, encontramos outras traduções: em francês, "l'angoissante possibilité de pouvoir" (Kierkegaard, 1990, p. 205); em espanhol, "a angustiosa possibilidad de poder" (Kierkegaard, 2012,

p. 92); em português, numa edição de 1968, aparece "a aflitiva possibilidade de poder" (Kierkegaard, 1968, p. 48). Em inglês, encontramos"possibility of being able" (Hong

\& Hong, 2000, p. 150).

Esta última tradução nos pareceu a mais próxima da escolhida pelo professor Valls (2010), em sua versão do livro O Conceito

de angústia (Kierkegaard, 1844/2010). Esta é a versão que está sendo utilizada neste nosso texto. No entanto, achamos

pertinente atentar para este detalhe, pois nos parece que o "ser-capaz-de" pode guardar algo como uma capacidade para, o que seria evitado se fosse mantida a tradução por "poder" que, a nosso ver, remete melhor ao sentido de possibilidade. distanciar de João para pensarmos sobre a angústia como uma determinação existencial, a fim de compreendermos o que está em questão para o autor em relação à escola da angústia.

\section{Considerações sobre angústia}

Para que possamos pensar acerca da escola da angústia é necessário compreendermos, primeiramente, o que Haufniensis quis dizer com angústia, de forma a que possamos esclarecer o sentido de se pensá-la como uma escola e da possível relação dessa escola com a psicoterapia. Nesse sentido, temos a angústia como objeto da reflexão psicológica na obra $O$ conceito de angústia (Kierkegaard, 1844/2010), trazida aos leitores como a atmosfera da possibilidade. Mas o que o pseudônimo Haufniensis (Kierkegaard, 1844/2010) quis dizer com a angústia ser a atmosfera da possibilidade? Para respondermos a esta pergunta somos levados pelo autor a pensarmos acerca de temas tais como a inocência, o eu (espírito), a culpa e a liberdade do individuo na existência. Para compreendermos cada um destes elementos faz-se necessário traçarmos suas relações com a própria angústia.

Segundo o autor, a angústia, de um modo ou de outro, é onde o homem sempre esteve, está e estará. Ela "é aquilo ao redor do que tudo gira" (Kierkegaard, 1844/2010, p. 47), mesmo que na inocência ela esteja apenas latente. Neste estado de inocência o homem é ignorância, ou seja, ele vive na fluidez dos atos e sem qualquer tipo de reflexão. E justamente por isso o autor nos diz que este estado é um nada, um nada que faz nascer angústia. E "esse é o segredo profundo da inocência, que ela ao mesmo tempo é angústia" (Kierkegaard, 1844/2010, p. 45). Ao afirmarmos que neste estado o homem é ignorante de ser angústia, imediatamente surge a pergunta: então, como ela pode se desvelar para o homem? A resposta aponta para o fato de que não há como descrevermos, paulatinamente, as escadas ou etapas que levarão o homem a se angustiar. A angústia simplesmente se dá, aparece num entre e a partir de lugar algum. É como no instante de um susto, de uma diferença em que o homem, subitamente, treme ou se ruboriza. Quando o proibido se mostra como aquilo que não pode, a possibilidade se revela como angústia. Ou seja, a possibilidade de poder o que não pode desvela o próprio espaço de possibilidade, o poder sim ou o poder não, e é aí que a angústia se revela, abrindo o que Haufniensis chamou de "a angustiante possibilidade de ser-capaz-de" (2010, p. 48) ${ }^{1}$. A possibilidade para o poder sim ou poder não aponta para a própria liberdade do homem. E, por isso Kierkegaard (2010, p. 45), na voz de Haufniensis, acentua que "a angústia é a realidade da liberdade como possibilidade antes da possibilidade", isto é, a angústia é a realidade da liberdade como possibilidade de ser-capaz-de, possibilidade de poder sim ou poder não. Isso significa que a liberdade acena para o caráter de possibilidade do homem.

Há uma relação direta entre liberdade e possibilidade, pois a liberdade oxigena possibilidades na realidade vivida. É o caráter de liberdade que nos faz sempre abertos aos possíveis. Isso leva-nos a concluir que não há como não termos possibilidades, não há como não sermos livres, mesmo que lidemos com nossa liberdade, ou seja, com nossas possibilidades, como se elas não existissem, como se tivéssemos apenas uma possibilidade tal qual um obsessivo, que não vê nada além do objeto de sua obsessão. Não há como fugir, pois, a liberdade está sempre aí, soprando possibilidades. Esse espaço de possibilidade é o próprio espaço da angústia, onde a liberdade que nós mesmos somos é desvelada. Será que a maioria dos homens vive a partir de uma entrega a este espaço de possibilidades, ou seja, será que os homens se tomam como liberdade? Guardemos esta pergunta para um pouco mais a frente nesta investigação.

Como vimos, na inocência a angústia está latente, pois se é ignorante de ser angústia, bem como o espírito - o eu - também se encontra latente neste estado de ignorância. A partir daí nos perguntamos, então, quando o espírito é posto? Para o pseudônimo Haufniensis (Kierkegaard, 1844/2010), o espírito não se mostra desde sempre, mas é posto no salto qualitativo, ou seja, é por um salto em que se instala a diferença de um 
estado a outro, e a determinação do espírito é posta pela culpa, caracterizando a saída da inocência. Dessa maneira, é por um salto qualitativo que o homem sai da inocência e descobre a si mesmo como culpado, cujo caráter aponta para uma responsabilidade do existir, para a determinação do espírito. Este salto acena para um movimento que surge sabe lá de onde, e se refere a lugar algum do qual pode surgir a culpa, visto que o salto não garante uma determinação específica, mas revela o espaço angustiante de poder ser.

A angústia se refere, justamente, a esse lugar algum, à indeterminação do sabe-se lá da onde, à possibilidade para a possibilidade que parece muito distante, mas que num piscar de olhos pode estar muito perto. Isso significa que a culpa, bem como o espírito, surgem a partir de um salto qualitativo que não tem seu lugar determinado e nem pode ter. Este salto surge como possibilidade por meio do espaço aberto pela angústia. A culpa, enquanto a determinação do espírito que devolve o homem a si mesmo, refere-se ao caráter intransferível do homem, ou seja, se refere ao fato de que ninguém pode ser culpado por ninguém, ninguém pode viver a vida de ninguém, e essa determinação recai na individualidade de cada um. Kierkegaard (1844/2010), na voz de Haufniensis, afirma que o espírito é um terceiro termo que se relaciona com a relação de dois termos, corpo e alma, determinação e indeterminação, em constante tensão. Como ele foi posto pelo salto a partir da possibilidade de ser culpado, ele está sempre em tensão com dois termos: a possibilidade (como liberdade) e a culpa (como determinação intransferível). A angústia é justamente esta tensão, que se descobre possibilidade de ser culpada e na descoberta já o é. Ela é este lugar ambíguo, paradoxal, a partir do qual o espírito está sempre se relacionando consigo mesmo, isto é, o espírito se relaciona consigo mesmo como angústia. Ser totalmente culpado ele não consegue, há sempre a possibilidade de se redimir. Ser totalmente livre, tampouco, em meio ao mar de possibilidades o espírito sempre se agarra numa boia. É nesse jogo, que ele ama e teme que a existência angustiante se constitui. Ora, ele ama, porque há uma boia a Ihe salvar, ora ele teme, porque não consegue segurar na boia eternamente. Maldita boia que tanto amo e que me escapa quando apenas the quero amar! diria o espírito. É como querer segurar o ar no peito para nunca mais ter que respirar, ele escapa, esvazia, e volta a encher. Tal reflexão revela a existência do homem como uma constante relação angustiante com algo tão impalpável.

Apresentamos a angústia como o lugar de tensão da existência, de tensão entre a culpa e a liberdade que constituem o espírito humano. Mas afinal, como se dá a relação do homem com a angústia que ele mesmo é? A angústia se mostra na própria existência, ela está sempre ali, à espreita, mas obscurecida. Vivemos como se não fôssemos angústia, como se não fôssemos esta tensão entre a liberdade de poder, e a culpa de ser. A angústia é essa vertigem, essa tontura, que diante do lugar que se encontra, não há mais chão, tampouco paredes ou teto, é só espaço, espaço de possibilidade, possibilidade de culpar-se uma vez mais. $\mathrm{E}$ diante da existência só Ihe resta gargalhar ironicamente, pois da mesma forma que ela pode nos tomar, ela pode nos dar. É exatamente porque ela tira o chão que um espaço se abre, um espaço de possibilidades e, por isso, podemos afirmar que ela é a atmosfera da possibilidade. A angústia olha para baixo e fica tonta, o mundo gira, e a liberdade traz possibilidades diversas, ela se agarra a qualquer coisa, um algo finito que possa fazer com que haja certa estabilização, mas aí já se encontra culpada, e a liberdade reaparece como arrependimento. Será que eu devia ter me segurado? Ela pergunta.

E aí nós perguntamos, será que existe a possibilidade de não se segurar? Seria este movimento infinito entre culpa e liberdade? Quais as relações que podem surgir a partir desta tensão que é espírito? Qual a importância da atmosfera da possibilidade para a Psicologia? Seria casual o fato $d^{\prime} O$ conceito de angústia ser um tratado psicológico, visto que a angústia é a atmosfera da possibilidade? A partir daí, como pensarmos o que Haufniensis afirma como a escola da angústia? Tratemos, inicialmente, da relação entre angústia, liberdade e modos de viver. 


\section{Angústia e liberdade}

A partir de agora podemos tentar compreender a relação de liberdade que o próprio espírito é, com a angústia, de forma a tornar possível pensarmos as relações existenciais concretas que podem surgir dessa tensão que o espírito mesmo é. Pode-se pensar, sobretudo, como a maior parte das pessoas se relaciona consigo mesmo como liberdade. Seriam elas todas livres? Se não, como, então, pensar a não liberdade? Este tema da liberdade e da indeterminação enquanto o lugar da angústia aparece, no pensamento do pseudônimo Haufniensis (Kierkegaard, 1844/2010), no centro da descrição sobre a real situação do homem e é considerado a partir da tensão entre limitação (determinação) e possibilidade. Para explicitar o âmbito do que venha a ser a liberdade do homem, Kierkegaard (1844/2010), na voz de Haufniensis, se pergunta pelo espaço e o tempo em que a liberdade se revela, o instante em que ela descobre a si mesma. O autor usa a figura histórica de Adão para mostrar que a liberdade se desvela no momento do rubor. É pelo ruborizar que aparece, para Adão, a diferença e, na diferença, a possibilidade. $\mathrm{O}$ rubor se constitui como elemento particular, ou seja, como rubor de Adão, que devolve Adão a si mesmo no julgar a si mesmo e ver a diferença entre ele e ele mesmo, a diferença entre ele e o resto da humanidade. Como singular Adão se destaca da humanidade, ou seja, de homem enquanto universal, e que não admite diferenciação, ele passa a ser Adão, o Adão que só ele mesmo pode ser. Esse instante de transformação, de diferenciação, ao qual Haufniensis denomina angústia, é o instante em que a liberdade e o espírito aparecem para Adão (neste caso é único), e subsiste como possibilidade para todo homem (toda a humanidade), pois “a cada momento as coisas se passam de tal modo que o indivíduo é ele mesmo e o gênero humano" (Kierkegaard, 1844/2010, p. 31), é singular e universal, subjetivo e objetivo. A partir daí podemos afirmar que a angústia surge como a atmosfera que reflete a liberdade como situação real da existência humana, em sua dupla constituição: por um lado a liberdade como um universal, que fala da impossibilidade de que o homem possa criar a si mesmo e de criar as condições de sua própria existência; por outro, a liberdade se refere à tarefa cotidiana de ter de ser o si mesmo que se é e de estar, continuamente, remetido à relação que se é.

Tal duplicidade revela-se na existência mesma, de modo que, em cada determinação a liberdade "pode" descobrir-se como possibilidades, num espaço aberto pela angústia. Este espaço revela um julgar a si mesmo, implicando, portanto, uma relação particular com o bem e o mal, sendo o bem a liberdade, e o mal a ausência de liberdade, de modo que um só aparece junto ao outro. Kierkegaard (1844/2010), pelo pseudônimo Haufniensis, descreverá, então, inúmeras estratégias que o homem pode usar para esconder de si mesmo a não liberdade lembrando, no entanto, que cada estado reflete o seu contrário. É a partir deste duplo movimento da liberdade que Kierkegaard (1844/2010), como Haufniensis, coloca a angústia como este espaço, este interlúdio em que a liberdade aparece para si mesma, e onde ela pode julgar a si mesma na tensão entre bem e mal. Julgando a si mesmo, o homem pode "ruborizar", ou seja, descobrir-se na não liberdade, domínio do pecado e do demoníaco. Mas a angústia guarda, também, a possibilidade de redenção, do retorno à liberdade, uma vez que, cada modo de existir constitui-se em uma possibilidade (liberdade) e nunca em uma necessidade.

A questão do bem e do mal merece ser vista com cuidado, pois apenas na liberdade (no bem) haverá a diferença entre bem e mal -e esta nunca aparece abstratamente, mas apenas concretamente. É por esta via que podemos pensar a diferença entre liberdade, entendida por Haufniensis como possibilidade para a possibilidade e livre arbítrio, compreendido a partir da perspectiva cristã do bem como sentido último do humano, em sintonia com a bondade divina e tornado efetivo pela identidade entre o querer e o ato de vontade. $\mathrm{O}$ telos do livre-arbítrio é a determinação de uma vida fundada na vontade, que é dona de si mesma. O bem e o mal aparecem, na perspectiva do livre arbítrio e da soberania da vontade, a partir da autodeterminação e pela disposição do eu de fundir-se apenas consigo mesmo. 
Kierkegaard (1844/2010), sob o pseudônimo Haufniensis, afirma que pensar o bem como exclusão do mal é pensá-lo abstratamente, tanto o bem quanto o mal (a liberdade e a não liberdade) são inerentes ao existir, constituindo-se em uma tensão que jamais se fecha, pois na liberdade sabe-se que "tudo é possível". A liberdade, então, não se deixa iludir, pois conhece seu limite, que é justamente a não liberdade, e espera o julgamento da angústia, pois a "angústia não é uma determinação da necessidade, mas tampouco o é da liberdade; ela consiste em uma liberdade enredada, onde a liberdade não é livre em si mesma, mas tolhida, não pela necessidade, mas em si mesma" (Kierkegaard, 1844/2010, p. 53). A angústia expressa, portanto, o duplo movimento da liberdade, ou seja, a situação ambígua do homem que não pode criar a si mesmo, não pode determinar as condições de sua existência e, ao mesmo tempo, tem de ser o si mesmo que é e pode ser.

O pseudônimo Haufniensis (Kierkegaard, 1844/2010) descreve algumas estratégias possíveis para que o homem esconda de si mesmo a liberdade que ele é, inscrevendo estas estratégias na tensão entre angústia do bem (angústia diante do mal) e angústia do mal (angústia diante do bem), ou seja, entre liberdade e não liberdade. O autor descreve a situação em que o indivíduo encontra-se livre (bem) e se angustia diante das possibilidades que o atraem e o enredam, que o convocam para a não liberdade (mal). Este estado caracteriza-se por uma disposição passiva e impotente diante do arrependimento. Neste modo de existir, a angústia é amenizada através da tristeza ou da lamentação, onde o arrependimento é passivo, sem forças para apropriar e corrigir o erro, pois na justificativa e na lamentação o homem se sente vítima do mundo e, como tal, desprovido de liberdade. Neste caso, o arrependimento não consegue torná-lo livre e ele se deixa iludir, de forma a, sempre, valer-se em uma ou outra regra de sabedoria da vida, consultando um ou outro, medindo-se pelo todo mundo (Kierkegaard, 1844/2010, p. 124).

Mas há, também, a situação em que a individualidade está no mal, na não liberdade e angustia-se pela retomada da liberdade (angústia do bem). Neste caso, a existência estabelece-se como uma constante fuga da liberdade e a angústia aparece para lembrá-la da possibilidade de retomar a liberdade. Kierkegaard (1844/2010), como Haufniensis, refere-se a este estado como o demoníaco, que é o espírito que se fecha em si mesmo e se cala na não comunicação (o hermético), escondendo-se em suas mentiras. É a não liberdade que quer se fechar sobre si mesma (Kierkegaard, 1844/2010, p. 126), mas que continua a se relacionar com a liberdade, por meio da angústia. A individualidade neste modo pode assumir vários estados: o hipocondríaco, o carrasco, o fazedor de sonhos, os grandes apaixonados, o enfadonho, o monótono ou uma vazia continuidade do nada. Neste estado o indivíduo sente pena de si mesmo, prefere tratar-se com "pílulas e pós", a dar um tratamento severo ao mal. Há, também, o estado em que a não liberdade aparece como perda pneumática, ou seja, como perda espiritual, a não liberdade se mostra numa relação teórica com a verdade e com o temporal. Falta a este existente coragem para manter-se firme na liberdade. A questão aqui é saber se o homem deseja deixar-se invadir em todo o seu ser pela verdade, se deseja assumir todas as consequências sem permitir-se nem uma escapatória em caso de dificuldades, pois o mal do nosso tempo é que a verdade cresce e a certeza decresce em busca de provas. A certeza aqui é o que compreendemos por subjetividade concreta e não abstrata.

Mas o que é certeza? Kierkegaard (2010, p. 152), como o pseudônimo Haufniensis, afirma que "dar uma definição neste caso não é, por certo fácil. Entretanto eu quero afirmar: é seriedade". No entanto, dar uma definição de seriedade já se constitui em uma leviandade, pois "a seriedade: ela é uma coisa tão séria que até mesmo uma definição já constitui uma leviandade." (Kierkegaard, $1844 / 2010$, p. 154). A seriedade aparece, neste contexto, oposta ao hábito, que é uma repetição sem originalidade, pois "o homem sério é, justamente sério, graças à originalidade com que ele retorna ao ponto inicial na repetição" (Kierkegaard, 1844/2010, p. 156). Conforme acentua Kierkegaard (1844/2010), 
pelo pseudônimo Haufniensis, ser formado pela angústia exige uma atitude séria na existência, principalmente, coragem para aprender com a angústia. A atmosfera de seriedade corresponde a uma abertura por deixar-se educar pela angústia. Considerando isso nós nos perguntamos: em que termos ele está pensando a possibilidade de uma escola da angústia? Isto é o que tentaremos pensar a seguir.

\section{A escola da angústia}

Kierkegaard (2010, p. 163) estima que quanto mais profundamente o homem se angustia, tanto maior ele é. Esse elevado valor que se confere a quem se angustia é um indicativo de que não devemos tomá-la como algo que é exterior ao homem, como nos mostraram as posições de não liberdade descritas acima. A perspectiva da angústia, quando tomada como se fosse algo fora do ser humano, pode se desenhar pela tentativa de se inscrever, por antecipação, uma pessoa na escola da angústia a partir do que se ouve dizer sobre ela, do que se toma, desavisadamente, por estar angustiado, como no conto que mostramos, onde aqueles que garantiram a João que ele iria aprender a ter medo fracassaram na sua promessa. Para Kierkegaard (1844/2010), sob o pseudônimo Haufniensis, é imprescindível experimentar-se a si mesmo como projetar-se para as possibilidades, para que se possa ser formado pela escola da angústia. A angústia não se mostra por procuração, não se lhe concebem mediações como se pudesse ser manejada teórico e tecnicamente. Ora, o que ela é entende-se a partir de um profundo segredo que se funda na possibilidade para a possibilidade, na possibilidade antes da possibilidade.

Podemos acreditar, inadvertidamente, que a possibilidade, característica da angústia, é um alento frente ao maciço e enfadonho tom da realidade. "É certo que se ouve com frequência o contrário: que a possibilidade é tão leve, a realidade, porém, tão pesada" (Kierkegaard, 1844/2010, p. 164). Quanto a isso, o pseudônimo Haufniensis (Kierkegaard, 1844/2010) dispara uma provocação: o que se toma como brilho e fulgor, o que se demarca como horizonte de possibilidades em termos de sucesso, sorte, vitória, e, hoje, poderíamos somar nessa lista, um esteticismo irrefreável e irrefletido que apela para o prazer, a sedução, o entretenimento, o consumismo, o dormir e acordar conectado, não é, na verdade possibilidade para a possibilidade, mas não passa de algo que atende aos reclames de uma moral vigente. Dessa maneira, é possível afirmarmos que não calculamos as possibilidades, ou seja, a possibilidade não é algo que possa ser planejado, antecipado para visar resultados tangíveis. Tal enquadre pertence à ordem do finito, de nossos cálculos acerca da "realidade". Já a possibilidade afirma a infinitude da existência. Nesse sentido, Kierkegaard (2010, p. 164), sob a voz de Haufniensis, nos diz que "aquele que é formado pela angústia é formado pela possibilidade, e só quem é formado pela possibilidade está formado de acordo com sua infinitude". Tentamos barganhar com o que para nós soa como possibilidade, mas, que não passa do universo tangível do finito. Tentamos "passar a conversa" (Kierkegaard, 1844/2010, p. 165) nas possibilidades, fugir delas, evitá-las, encobri-las, adiá-las, e, até, como se fosse possível, suprimi-las. Mas quem foi educado na escola da possibilidade aprendeu que não se pode exigir absolutamente nada da vida. Exigir da vida é barganhar com ela. É tratá-la como coisa entre coisas como se costuma fazer quando estamos naquilo que o autor chamou de "escola da finitude".

Se a possibilidade pode doer, pois pode ser interpretada como algo sofrido, afinal, "perdição, aniquilamento moram na porta ao lado de qualquer homem" (Kierkegaard, $1844 / 2010$, p. 165), as avaliações sobre se valeu a pena ou não se lançar nas possibilidades nada podem nos ensinar na escola da angústia, pois são feitas a posteriori. Afirma o pseudônimo Haufniensis (Kierkegaard, 1844/2010): "Não, na possibilidade tudo é igualmente possível, e aquele que, em verdade, foi educado pela possibilidade entendeu aquela que o apavora tão bem quanto aquela que Ihe sorri" (Kierkegaard, $1844 / 2010$, p. 164). Por fim, entendeu a ambiguidade do amor e do temor que a angústia nos traz. Nossa prosa lembra-nos o entusiasmo que Heidegger (1952/2002, p. 31) nutre por Hölderlin ao plagiar sua 
sentença: "onde está o perigo, está aquilo que salva". Para Kierkegaard (1844/2010), sob o pseudônimo Haufniensis, é na angústia que o homem se eleva, e é na angústia que o homem pode se afundar. "Na realidade, ninguém se afundou tanto que não pudesse afundar-se ainda mais" (Kierkegaard, 1844/2010, p. 167).

Para que alguém se forme nesta escola, portanto, é preciso ser honesto quanto às possibilidades (a liberdade que se é). A própria possibilidade desdobra a finitude em infinitude: descobre as finitudes, as condições concretas da existência, descobre "a vida mais presa ao dia a dia" (Kierkegaard, 1844/2010, p.166). Mas, ao mesmo tempo, as idealiza, apontando a existência para a infinitude. Essa passagem da realidade à possibilidade dá-se mergulhando a pessoa na angústia, até que ela vença as determinações finitas na antecipação da fé. Haufniensis, concordando com Hegel, apresenta a fé como "a certeza interior que antecipa a infinitude" (Kierkegaard, 1844/2010, p. 165). É apenas na imersão do constante jogo existencial de possibilidades e determinações (infinitude e finitude, liberdade e culpa), que acontece, no instante, o aprendizado, e este instante pode dar lugar a uma transformação. Neste ponto de nossa escrita, nos resta tecer considerações para o exercício clínico de uma Psicologia kierkegaardiana.

\section{Angústia e Psicoterapia}

Vamos retomar o conto de Grimm sobre João sem Medo para pensarmos a atuação psicoterápica com base na escola da angústia. Foram vários os caminhos que o pai, os irmãos e os amigos de João procuraram a fim de que o menino encontrasse um rumo na vida. Mas, ainda que "aparentemente" isso de nada lhe adiantasse, João queria aprender a temer. Apesar de inúmeras tentativas, foi na própria existência que o menino, de súbito, estremeceu. Convém investigar: o que aconteceu para que um espaço se abrisse para o aparecimento do medo? João queria temer, porém seu querer não era suficiente para que acontecesse uma transformação. Aqueles que tentavam ajudá-lo acreditavam que bastava utilizar suas próprias experiências e técnicas para alcançar o resultado. Porém, isto também se mostrou insuficiente. João se encontrava em completa inocência e falta de seriedade, desconhecendo o espaço em que tudo é possível. Repentinamente, João assusta-se, treme e, então, o espírito desperta do estado de latência em que se encontrava, abre-se a atmosfera da angústia e ele se descobre como possibilidade (liberdade). João, que vivia na ignorância de sua situação, descobriu-se temeroso, culpado e vulnerável. Assim parece, também, desvelarse aquilo que Kierkegaard (1844/2010), na voz de Haufniensis, denomina de escola da angústia. Discorreremos sobre a questão que estabelecemos no início desta discussão: Qual a relação dessa escola com a psicoterapia?

Comumente a psicoterapia se dá a partir dos mesmos pressupostos utilizados no modo como João foi sendo orientado: os psicoterapeutas traçam caminhos no sentido de que as crianças aprendam a lidar com as demandas de seu mundo e se tornem adultos produtivos. A angústia, o medo e a improdutividade tendem a ser combatidos, já que são tomados como respostas desadaptadas ao mundo. A psicoterapia, como comumente é conhecida, constitui-se em uma técnica, que possui instrumentos e ferramentas eficazes, sustentados teoricamente, capazes de desvendar os segredos e verdades que se encontram no indivíduo. Onde aquele que não conhece a verdade de si pode, uma vez conquistando-a, superar os seus conflitos e assim ganhar liberdade, autodomínio e não mais se angustiar. Certamente, o caminho traçado por esses estudiosos não é a escola da angústia a que se refere o pseudônimo Haufniensis (Kierkegaard, 1844/2010). Mas a que, afinal, se refere a psicoterapia existencial baseada na escola da angústia?

Ressaltaremos, primeiramente, as considerações de Haufniensis sobre a Psicologia de sua época. O escritor afirma que a Psicologia estava totalmente equivocada ao tomar o seu objeto de estudo como algo que tem suas bases na fisiologia. Com isso, ele, já em 1844, oferecia argumentos acerca da autonomia da Psicologia que, durante longo tempo, os estudiosos do psiquismo humano ignoraram e só vieram 
a consegui-lo aproximadamente 40 anos depois de Kierkegaard, com Henri Bergson (1859-1940) e Franz Brentano (1838-1917).

Para Kierkegaard (1844/2010), sob o pseudônimo Haufniensis, a Psicologia deveria se ocupar com a existência humana em suas diferentes expressões, a partir da angústia e da liberdade. O que daí se revela é uma autonomia diante da biologia e da fisiologia, e uma retomada do espaço da existência como espaço de possibilidade e não cálculo, tornando possível, dessa forma, uma reinterpretação da própria Psicologia. De modo que, nesta abordagem saímos da base das ciências naturais e da ideia de uma subjetividade, lógica ou empírica, e pensamos o modo em que o homem se expressa em sua concretude existencial. A subjetividade, aqui, se constitui como a tensão mesma em que a existência sempre se dá, ou seja, como liberdade e culpa, bem e mal, indeterminação e determinação. Essa reinterpretação da Psicologia não dispõe de fundamentos teóricos e práticos, tendo como base uma investigação existencial no solo da angústia como possibilidade. Ao psicoterapeuta cabe, desta maneira, identificar os modos pelos quais o existente tenta manter obscurecida a sua situação de tensão e de angústia. Mas como atuará então o profissional psi que, deste modo, pensa a existência?

Ao psicólogo, parafraseando Kierkegaard (1859/1988), cabe despertar aquele que se encontra na ilusão, para que assim o iludido possa desvelar a sua situação de angústia que sempre está ali, na espreita, mas obscurecida. Porém, como despertar o outro de seu estado de sonolência? O psicoterapeuta existencial reconhece a sua impotência, jamais assumindo o lugar do especialista que conhece as verdades do psiquismo. Reconhecendo, deste modo, que a angústia é algo que jamais pode ser superada. Antes, ele vê na angústia a expressão do apelo pela retomada da liberdade, da tensão que se é (Feijoo \& Protasio, 2011). Por isso, humildemente, ele tenta acompanhar a possibilidade de que as transformações existenciais possam acontecer, mas sabe que esse instante, esse salto, acontece como um susto. Ele apenas participa daquilo que inquieta aquele que the pede ajuda, não podendo assumir a posição que o outro deve tomar, pois se o fizer embala mais ainda o sono em que o outro se encontra. É no não iludir o outro que a participação do psicoterapeuta existencial é decisiva para que aconteça uma possível transformação da sua realidade como possibilidade. E, é pela escola da angústia que a psicoterapia existencial vai se apropriar de um espaço propício para o despertar da liberdade, que se encontra no fundo da não liberdade. E para que, uma vez despertos, os iludidos possam, na seriedade da existência, permitir-se aprender na angústia a sua verdade.

Mas retornemos a João Sem Medo para, lembrando seus passos, respondermos acerca do que é necessário em uma relação psicoterapêutica para que a transformação aconteça. Primeiramente, a transformação de João acontece de modo súbito, inesperado, por isso, diz Grimm, ele se assusta. Com isso, esclarece-se que a transformação não necessariamente acontece pela vontade e pelo acúmulo de experiências, logo é um salto (qualitativo). Acreditamos que não é aquilo que o psicoterapeuta faz, na ordem do positivo e do cálculo (quantitativo), que provoca a transformação. Ao contrário, é na escola da angústia que a psicoterapia existencial conquista um aprendizado no sentido de encontrar o seu espaço de atuação. $\mathrm{O}$ psicoterapeuta aprende que o despertar do espírito exige o susto, o rubor, a experiência do inesperado e para tanto, precisa poder manter, na atmosfera da angústia, o espaço de tensão entre a culpa e a liberdade, sustentando a possibilidade de transformação, sem propor nenhuma medida ou orientação. Assim como os peixinhos saltitantes, postos na barriga de João Ihe trazem a possibilidade de surpreender-se, é preciso que o psicoterapeuta possa aguardar o momento propício para que o inesperado se dê, trazendo a possibilidade de uma transformação existencial. 


\section{Ana Maria Lopez Calvo de Feijoo}

Professora Adjunta da Graduação e do Programa de Pós-Graduação em Psicologia Social da Universidade do Estado do Rio De Janeiro - RJ. Brasil.

E-mail: ana.maria.feijoo@gmail.com

\section{Débora Gill}

Doutoranda em Filosofia pela Pontifícia Universidade Católica do Rio De Janeiro - RJ. Brasil. Email: debora_gill@yahoo.com.br

\section{Luiz José Veríssimo}

Doutor em Filosofia pela UERJ e Professor da Universidade Veiga de Almeida - RJ. Brasil.

\section{Myriam Moreira Protasio}

Doutoranda em Filosofia e Professora substituta da Universidade do Estado do Rio de Janeiro - RJ. Brasil.

\section{Endereço para envio de correspondência:}

Rua Barão de Pirassinunga, 62. Tijuca. CEP: 20520-170. Rio de Janeiro - RJ. Brasil.

Recebido 25/03/2013, Aprovado 08/04/2015. 
Bergson, H. (1988) Ensaio sobre os dados imediatos da consciência. (J.S.Gama, trad.). Lisboa: edições70. (Original publicado em 1889)

Brentano, F.(1995) Descriptive Psychology. ( Benito Muller, trad.). London: Routledge. (Original publicado em 1903)

Feijoo, A. M. L. C. (2000). A escuta e a fala em psicoterapia: Em uma perspectiva fenomenológico- existencial. São Paulo: Vetor.

Feijoo, A. M. L. C., \& Protasio, M. M. (2011). Análise existencial: Uma psicologia de inspiração kierkegaardiana. Arquivos Brasileiros de Psicologia. 63(3), 72-98.

Grimm, J. W. (2004). João sem medo. In H. C. Andersen, \& J. W. Grimm (Irmãos Grimm). Contos infantis (J. Andrada, trad.). Recuperado em 16 de setembro de 2012, de http://www.psbnacional.org.br/bib/ b214.pdf_file:///C|/cursos_e_livros_cd/ Triagem/000000-contosin.html

Heidegger, M. (2002). Ensaios e conferências. (E. C. Leão, G. Fogel e M. S. C. Schuback, trads.). Petrópolis; Vozes e Bragança Paulista:
Universidade São Francisco. (Original publicado em 1953).

Hong, H. V., \& Hong, E. H. (2000). The essencial Kierkegaard. Princenton, NJ: Princenton University Press.

Kierkegaard, S. (2012). El concepto de la angustia. Madrid: Alianza.

Kierkegaard, S. (1988). Mi punto de vista. Madrid: Aguilar. (Original publicado em 1859).

Kierkegaard, S. (1990). Miettes philosophiques, le concept de l'angoisse, traité du désespoir. Paris: Gallimard. (Original publicado em 1844)

Kierkegaard, S. (1968). O conceito de angústia. São Paulo: Hemus. (Original publicado em 1844).

Kierkegaard, S. (2010). O conceito de angústia. (A. L. M. Valls, trad). Petrópolis: Vozes. (Original publicado em 1844).

Valls, A. L. Posfácio. (2010). In S. Kierkegaard. O conceito de angústia. (A. L. M. Valls Trad.). Petrópolis: Vozes. 